\title{
Admissions to hospital caused by adverse drug reactions: cross sectional incidence study
}

Pierre Pouyanne, Françoise Haramburu, Jean Louis Imbs, Bernard Bégaud for the French Pharmacovigilance Centres

Centre de

Pharmacovigilance,

Département de

Pharmacologie,

Université Victor

Segalen, CHU,

F-33076 Bordeaux,

France

Pierre Pouyanne

assistant professor

Françoise

Haramburu

clinical

pharmacologist

Bernard Bégaud

professor of

pharmacology

Centre Régional de

Pharmacovigilance

Alsace, Service de

Pharmacologie

Clinique, Hôpitaux

Universitaires,

F-67091

Strasbourg, France

Jean Louis Imbs

professor of

pharmacology

Correspondence to:

F Haramburu

francoise.

haramburu@

pharmaco.

u-bordeaux2.fr

BMJ 2000;320:1036

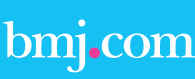

A list of investigators from the participating centres appears on the BMJ's website
The incidence of adverse reactions to drugs has been assessed with prospective epidemiological studies conducted within single units, departments, or hospitals. ${ }^{1-3}$ Because of the variability of the results and a lack of representativeness, it is difficult to confidently extrapolate these results to a national level. To calculate the incidence of admissions caused by adverse drug reactions we conducted a prospective cross sectional study of a representative nationwide sample of medical wards in public hospitals.

\section{Methods and results}

Between 2 March and 20 April 1998, the study was conducted for 14 days in each of a representative sample of medical departments in French teaching hospitals and general hospitals. The sample size required was calculated from the results of a pilot study. ${ }^{4}$ All patients admitted to the departments sampled were included in the study. Each patient was assessed by a team of local clinicians and pharmacologists to determine whether the admission was the result of an adverse drug event.

A case was defined as a patient admitted because of an adverse drug reaction. ${ }^{5}$ Information collected for each case included the patient's drug treatment, characteristics and evolution of the adverse reaction, and the duration of the hospital stay. All cases were later validated by an independent committee.

The $95 \%$ confidence interval was calculated for the normal distribution of complex sampling when requirements for using such a method were fulfilledthat is when $n>20$. The Poisson distribution was used when the design effect was negligible $(<1.5)$. The $\chi^{2}$ test and tests of analysis of variance were also used.

In all, 3137 patients were admitted to the 62 medical departments of the 33 hospitals in the study. Altogether $100(3.19 \%)$ patients had been admitted to hospital because of an adverse drug reaction (95\% confidence interval $2.37 \%$ to $4.01 \%$ ) (table). These patients tended to be older than those admitted for other reasons ( $60.5 \mathrm{v}$ 52.9 years, $\mathrm{P}=0.009$ ) and were more likely to be female $(57 / 100(57 \%)$ v $1457 / 3137 \quad(46 \%), \quad \mathrm{P}=0.03)$. The incidence of admission for an adverse reaction increased with age $(\mathrm{P}=0.005)$. Gastrointestinal complications were the most frequent cause of admission for an adverse reaction (27/100). Nine of the 100 admissions resulted from gastrointestinal bleeding caused by non-steroidal anti-inflammatory drugs (incidence $0.29 \%, 0.13 \%$ to $0.55 \%)$; 13 patients were admitted with a haemorrhage caused by anticoagulant drugs (data not shown). Of the 193 drugs identified as being associated with admission, cardiac stimulants and antiarrhythmic drugs were the most common, accounting for $18(9 \%)$ of the drugs; they were followed by antineoplastic drugs (16/193; 8\%), antithrombotic drugs $(15 / 193 ; 8 \%)$, and antihypertensive drugs $(15 / 193 ; 8 \%)$.

Seventy eight of the patients recovered completely, nine had irreversible lesions, and nine died. Among
Incidence of adverse drug reactions in 3137 hospital admissions

\begin{tabular}{lccc} 
& $\begin{array}{c}\text { No of } \\
\text { admissions }\end{array}$ & $\begin{array}{c}\text { No of adverse } \\
\text { drug reactions }\end{array}$ & Incidence (\%; 95\% Cl) \\
\hline Age: & & & \\
\hline$\leqslant 15$ & 525 & 10 & $1.91(0.91$ to 3.5$)$ \\
\hline 16 to $\leqslant 64$ & 1184 & 31 & $2.62(1.57$ to 3.66$)$ \\
\hline$\geqslant 65$ & 1428 & 59 & $4.13(2.72$ to 5.54$)$ \\
\hline Total & 3137 & 100 & $3.19(2.37$ to 4.01$)$ \\
\hline
\end{tabular}

those who died, the adverse effect was the direct cause of death in four cases $(0.12 \%, 0.034 \%$ to $0.33 \%)$. Three patients were lost to follow up. The average stay in hospital was 9.7 days. Using national statistics we estimated that each year in France 134159 (97 382 to 170777 ) admissions were caused by adverse drug reactions (1 285256 (920486 to 1641263 ) days spent in hospital).

\section{Comment}

This is the first prospective, national study conducted to determine the incidence of hospital admissions related to adverse drug reactions. Our findings are similar to results obtained by two meta-analyses. In Australia an incidence of between $2.4 \%$ and $3.6 \%$ was found ${ }^{3}$ and in the United States an incidence of between 3.1\% and $6.2 \%$ was found. ${ }^{1}$ The mortality found in our study is the same as that found in the United States $(0.13 \%, 0.04 \%$ to $0.21 \%)$. Older age and female sex are considered to be risk factors for hospital admissions caused by adverse drug reactions; this was confirmed by our results.

Admissions caused by adverse reactions are only one aspect of drug related morbidity and account for about $10 \%$ of the adverse effects observed in hospitals. ${ }^{4}$ A larger proportion of adverse effects probably occurs in the community and never leads to admission.

We thank the physicians who participated in this study as well as the members of the expert committee:Joel Ankri, G Birry, Anne Castot, Dominique Costagliola, Jean Claude Evreux, M Imler, Claudine Soubrié, and Marie Welsch. We also thank Elsa Diarte, Didier Ekouevi, Françoise Ferval, Betty Laborde, Sandy Maumus, Ghada Miremont, Madeleine Mimiague, Eric Pohier, Caroline Roussillon, and Hélène Théophile for their help with randomisation and coding data, and Simone MathoulinPelissier for suggestions about the analysis.

Contributors: PP, FH, JLI and BB jointly analysed and wrote up the study and will act as guarantors.

Funding: Agence française du médicament.

Competing interests: None declared.

1 Lazarou J, Pomeranz BH, Corey PN. Incidence of adverse drug reactions in hospitalized patients. JAMA 1998;279:1200-5

2 Einarson TR. Drug-related hospital admissions. Ann Pharmacother 1993;27:832-8.

3 Roughead EE, Gilbert AL, Primrose JG, Sansom LN. Drug-related hospital admissions: a review of Australian studies published 1988-1996. Med J Aust 1998;165:405-8.

4 Imbs JL, Pouyanne P, Haramburu F, Welsch M, Decker N, Blavac JP, et al. Iatrogénie médicamenteuse: estimation de sa prévalence dans les hôpitaux publics français. Therapie 1999;54:21-7.

5 World Health Organization. International drug monitoring: the role of the hospital. Geneva: World Health Organization, 1996. (Technical report series: No 425.)

(Accepted 13 January 2000) 